\title{
Ciprofloxacin Hydrochloride Encapsulated into PLGA Nanoparticles for Drug Delivery Application: Fractional Factorial Design
}

\author{
Tajudeen Adebileje ${ }^{1,2 *}$, Sikiru Adebileje ${ }^{3}$, P. O. Aye ${ }^{2}$ \\ ${ }^{1}$ Department of Medical Nanotechnology, School of Advanced Technologies in Medicine, Tehran University of Medical \\ Sciences-International Campus (TUMS-IC), Tehran, Iran \\ ${ }^{2}$ Department of Mathematical Sciences, Adekunle Ajasin University, Akungba-Akoko, Ondo State, Nigeria \\ ${ }^{3}$ Department of Medical Physics and Biomedical Engineering, Tehran University of Medical Sciences-International Campus \\ (TUMS-IC), Tehran, Iran \\ Email: *tajudeenayodele@gmail.com, ${ }^{*}$ tajudeenadebileje@gmail.com, *t-ayodeleadebileje@razi.tums.ac.ir
}

How to cite this paper: Adebileje, T., Adebileje, S. and Aye, P.O. (2018) Ciprofloxacin Hydrochloride Encapsulated into PLGA Nanoparticles for Drug Delivery Application: Fractional Factorial Design. Open Access Library Journal, 5: e4294. https://doi.org/10.4236/oalib.1104294

Received: December 28, 2017

Accepted: February 25, 2018

Published: February 28, 2018

Copyright $\odot 2018$ by authors and Open Access Library Inc.

This work is licensed under the Creative Commons Attribution International License (CC BY 4.0).

http://creativecommons.org/licenses/by/4.0/

\section{(c) (i) Open Access}

\begin{abstract}
Over several decades, poly (lactic-co-glycolic acid) (PLGA) have been widely used as Micro- and Nano-carriers of therapeutic agents for drug delivery applications. However, encapsulation process of therapeutic agents into PLGA Nanoparticles (NPs) necessitates a defined step to understand the effects and interactions of parameters involved in production process. In pharmaceutics formulations, compared to one factor at a time (OFAT) approach, statistical design of experiments (DOE) supersedes OFAT approach due to limited number of experiments required to investigate effects and interactions of a process parameters. The major objectives of the present study were to: 1) prepare and understand the effect of selected formulation parameters on particles size and drug recovery of PLGA NPs encapsulating Ciprofloxacin Hydrochloride (Cip- $\mathrm{HCl}$ ) using a fractional factorial design (FFD) as a DOE approach; 2) understand the in-vitro release of $\mathrm{Cip}-\mathrm{HCl}$ from PLGA NPs. Cip- $\mathrm{HCl}$ loaded PLGA were prepared by $\mathrm{W}_{1} / \mathrm{O} / \mathrm{W}_{2}$ double emulsion solvent evaporation (DESE) method using poly-vinyl alcohol as a stabilizer. The Sizes of NPs were within $202 \mathrm{~nm}$ to $530 \mathrm{~nm}$ and percentage $\mathrm{Cip}-\mathrm{HCl}$ recovered from dried NPs were within $1.7 \% \mathrm{w} / \mathrm{w}$ to $15.7 \% \mathrm{w} / \mathrm{w}$. Increasing concentrations of PLGA and Cip- $\mathrm{HCl}$ was observed to increase NPs size. Increasing PVA concentration was observed to either reduce or increase NPs size. Increasing PLGA concentration was observed to increase the amount of $\mathrm{Cip}-\mathrm{HCl}$ recovered. Within 1 - 24 hours, optimized formulations shows a controlled release of Cip- $\mathrm{HCl}$ from PLGA NPs.
\end{abstract}

\section{Subject Areas}

Medicinal Chemistry, Pharmacology 


\section{Keywords}

Ciprofloxacin Hydrochloride, PLGA Nanoparticles, Drug Recovery, Double Emulsion Solvent Evaporation, Fractional Factorial Design

\section{Introduction}

Recently, the branch of nanomedicine that involves encapsulation of active therapeutic agents into micro and nano-particulate delivery system overcomes certain hurdles, such as protection of therapeutic agents against in-vivo chemical and enzymatic degradation, reduce administered dosage and toxic effects, improved efficacy and controlled release of therapeutic agents [1]. Aside delivery systems using particles, carriers such as nanobubbles can encapsulate either therapeutic agents or NPs within and unto the bubble structure, and these carriers are known to perform both diagnostic and therapeutic functions in cancer therapy [2]. Nanoparticles (NPs) encapsulating therapeutic agents are able to deliver therapeutic agents to less accessible sites when compared with other dosage form and consequently increases the bioavailability of the therapeutic agents due to their high surface area to volume ratio [3]. Therapeutic agents such as ciprofloxacin hydrochloride ( $\mathrm{Cip}-\mathrm{HCl}$ ) which is an antibiotic and a second generation of fluoroquinolone demonstrate a broad spectrum of activity that consequently results in the death of bacterial infections [4]. Implantable ciprofloxacin formulations have been shown to be effective in the treatment of skin and bones infection [5], and have been put forward for management and prevention of endophthalmitis [6] [7].

Nanomaterials such as natural and synthetic polymers can be fabricated into micro- and NPs so as to encapsulate and deliver therapeutic agents or target damaged cells via different route of administration. PLGA as a synthetic polymer have been used in detailed degree for both encapsulation and delivery of therapeutic agents. PLGA particles encapsulating therapeutic agents are commonly prepared by nanoprecipitation (solvent diffusion or solvent displacement), solvent evaporation (either single or double emulsion), salting out, spray drying and solvent extraction techniques [8]. Among these methods, $\mathrm{W}_{1} / \mathrm{O} / \mathrm{W}_{2}$ double emulsion solvent evaporation methods are used to encapsulation hydrophilic therapeutic agents. However, obtaining the desired particles properties in terms of size and drug content of particles depends on both the composition (amount) of material used and the technical parameters (such as sonication and stirring parameters) for production.

Cip- $\mathrm{HCl}$ as a hydrophilic agent is sparingly soluble from $10-33 \mathrm{mg} / \mathrm{ml}$ specifically at $10 \mathrm{mg} / \mathrm{ml}$ in aqueous acidic solution [9] [10]. Cip- $\mathrm{HCl}$ could be encapsulated into PLGA matrix using double emulsion solvent evaporation method. A study prepared positively charged ciprofloxacin-loaded NPs by water-in-oil-in-water (w/o/w) double emulsion using Eudragit ${ }^{\oplus}$ RS100 and RL100 
as non-biodegradable polymers and PLGA as a biodegradable polymer [11]. However, the production of PLGA NPs encapsulating Cip- $\mathrm{HCl}$ requires designed procedure, so as to understand the effects and interactions of its production parameters.

Design of experiments (DOE) such as full factorial, central composite, Box-Behnken Design (BBD) and fractional factorial design (FFD) are some useful approach that are widely used in pharmaceutical development to understand the effect of process parameters affecting experimental outcome. Considering the multiple formulation parameters (both technical and composition parameters) in double emulsion solvent evaporation method. While keeping some technical parameters fixed, no work so far as detailed the effects of composition parameters affecting the particles size of PLGA encapsulating $\mathrm{Cip}-\mathrm{HCl}$, and precisely on the percentage of Cip- $\mathrm{HCl}$ recovered from PLGA NPs using a FFD. Using BBD as a response surface methodology based on DOE, the effect of selected process parameters of PLGA NPs encapsulating bovine serum albumin was recently investigated [12].

In this study, FFD was used to plan and analyze experiments of PLGA NPs encapsulating Cip-HCl. NPs were prepared by double emulsion solvent evaporation method and we attempt to investigate the effect of composition parameters on particles size of PLGA NPs encapsulating $\mathrm{Cip}-\mathrm{HCl}$ and the percentage drug recovered (DR) from PLGA NPs. Technical experimental parameters of double emulsions were kept constants, concentrations of PLGA, Cip- $\mathrm{HCl}$ and PVA were selected to be the three composition parameters affecting particles size and percentage DR. Furthermore, we investigated the in-vitro release of Cip- $\mathrm{HCl}$ loaded PLGA NPs from validated and optimized formulations derived from FFD.

\section{Materials and Methods}

\subsection{Materials}

High purity medical grade PLGA (50:50 with molecular weight $50 \mathrm{kDa}$ ) was purchased from Shenzhen Esun Industrial Co., LTD (Shenzhen, China). Polyvinyl alcohol (PVA) was purchased from VAM \& P.VAL Co. Ltd (Tokyo, JAPAN). Cip-HCl was purchased from Sigma-Aldrich Inc. (St. Louis, MO). Chloroform (molecular mass $=119.3 \mathrm{~g} /$ mole, spec. density: $1.48 \mathrm{~g} / \mathrm{cm}^{3}$ ) was purchased from Dr. Mojallali chemical complex Co (Tehran, Iran).

\subsection{Design of Experiments}

In experiments, factors are defined specifications at a given extent or levels e.g. reaction time, concentration, temperature, $\mathrm{pH}$, etc. that affects the outcome of a procedure. The classically applied univariate one-factor at-a-time (OFAT) approach for experimental validation has disadvantages, such as the interactions between factors of an experimental outcome are not taken into consideration. Compared to OFAT approach, statistical DOE can be used to study interactions 
between experimental process parameters [13]. Full factorial DOE, is a branch of $\mathrm{DOE}$, the general rule to determine the total number of experiments follows the formula $\mathrm{L}^{\mathrm{K}}$ (where $\mathrm{K}$ is the numbers of factors at $\mathrm{L}$ levels of each factor to study). Therefore, factorial design with 2 factors at 2 levels of each factor requires $L^{\mathrm{K}}=$ $2^{2}=4$ experiments, factorial design with 2 factors at 3 levels of each factor requires $3^{2}$ experiments, and that of 3 factors at 3 levels of each factor requires $3^{3}=$ 27 experiments. However, disadvantages in full factorial DOE is that the numbers of experiments increases as $\mathrm{K}$ and $\mathrm{L}$ increases.

A fractional factorial DOE is defined as a fraction of a full factorial design, which follows a general rule of $\mathrm{L}^{\mathrm{K}-\mathrm{p}}$ where $\mathrm{p}$ is the fraction of original factorial design. The subset or fraction of full factorial design is chosen so as to report information about most relevant features of the problem studied. Therefore, a fraction of 4 factors at 3 levels of each factors of factorial experiments generates $3^{4-1}=27$ experiments instead of 81 factorial experiments, also a fraction of 3 factors at 3 levels of each factors of factorial experiments generates $3^{3-1}=9$ experiments instead of 27 factorial experiments.

\subsection{Experimental Formulation}

Water-in-Oil-in-Water $\left(\mathrm{W}_{1} / \mathrm{O} / \mathrm{W}_{2}\right)$ double emulsion solvent evaporation method was designed for encapsulation of Cip- $\mathrm{HCl}$ loaded into PLGA NPs. While setting the volume of inner aqueous phase $\left(\mathrm{W}_{1}\right)$ to $1 \mathrm{ml}$, volume of organic phase (O) to $4 \mathrm{ml}$, volume of external aqueous phase $\left(\mathrm{W}_{2}\right)$ containing PVA to $25 \mathrm{ml}$. Technical parameters such as, first emulsion sonication process at $100 \mathrm{~W}$ for 60 sec, second emulsion sonication process at $100 \mathrm{~W}$ for $120 \mathrm{sec}$, organic solvent (chloroform) evaporation rate at $1000 \mathrm{rpm}$ for 4 hours at room temperature, NPs collection during centrifugation at $12,000 \mathrm{rpm}$ for 50 minutes were also kept constant.

Concentrations of Cip- $\mathrm{HCl}$ dissolved in inner aqueous phase, PLGA dissolved in organic phase (chloroform) and PVA at the external aqueous phase (distilled water) were suggested to be the 3 independent preparation parameters affecting particles size and percentage DR. Considering 3 different level of each composition parameters (see Table 1), $3^{3}$ FFD was designed using STATISTICA ${ }^{\mathrm{TM}}$

Table 1. Concentration levels of composition parameters considered for experimental design.

\begin{tabular}{cccccc}
\hline & Factors & Composition parameters & $\begin{array}{r}\text { Low } \\
\text { level }\end{array}$ & $\begin{array}{c}\text { Centre } \\
\text { level }\end{array}$ & $\begin{array}{c}\text { High } \\
\text { level }\end{array}$ \\
\hline 1 & $\begin{array}{c}\mathrm{X}_{1} \\
(\% \mathrm{w} / \mathrm{v})\end{array}$ & Concentration of PLGA in organic phase (Chloroform) & 1.0 & 1.5 & 2.0 \\
2 & $\begin{array}{c}\mathrm{X}_{2} \\
(\% \mathrm{w} / \mathrm{v})\end{array}$ & $\begin{array}{c}\text { Concentration of Cip-Hcl in inner aqueous } \\
\text { phase (Distilled water) }\end{array}$ & 0.5 & 1.0 & 1.5 \\
3 & $\begin{array}{c}\mathrm{X}_{3} \\
(\% \mathrm{w} / \mathrm{v})\end{array}$ & $\begin{array}{c}\text { Concentration of PVA in external aqueous } \\
\text { phase (Distilled water) }\end{array}$ & 0.1 & 0.2 & 0.3 \\
\hline & & & & & \\
\hline
\end{tabular}


Ver.12.0 software package (Stat Soft Inc., USA) to generate 9 experiments (see Table 2). PLGA NPs were prepared, the particles size and percentage DR were also determined. Statistical analysis on both particles size and DR was carried out using two-way linear-linear interactions on composition parameters.

A regression equation was obtained from statistical analysis for the prediction of both particles size and percentage DR. To validate the regression equations obtained from FFD, Two (2) additional experiments were carried out after the predicting the values of NPs size and percentage the regression equations. Finally, in-vitro release of Cip- $\mathrm{HCl}$ from PLGA NPs was then performed on the two optimized formulations.

\subsection{Preparation of PLGA Nanoparticles Encapsulating Cip-Hcl}

Table 2 demonstrates parameters considered for 11 experiments of Cip-Hcl prepared $\mathrm{W}_{1} / \mathrm{O} / \mathrm{W}_{2}$ double emulsion solvent evaporation method. Briefly, first emulsion $\left(\mathrm{W}_{1} / \mathrm{O}\right)$ was obtained by dissolving Cip- $\mathrm{HCl}$ into $1 \mathrm{ml}$ of distilled water and was emulsified with $4 \mathrm{ml}$ organic phase (chloroform) containing PLGA using a probe sonicator, (Development of Ultrasound Technology (Tehran, Iran)). The $\mathrm{W}_{1} / \mathrm{O}$ emulsion was dispersed into $25 \mathrm{ml}$ of distilled water containing PVA to obtain a $\mathrm{W}_{1} / \mathrm{O} / \mathrm{W}_{2}$ double emulsion (Table 1 and Table 2). The $\mathrm{W}_{1} / \mathrm{O} / \mathrm{W}_{2}$ double emulsion were sonicated and organic solvents were allowed to evaporate under magnetic stirrer (1000 rpm) for 4 hours at room temperature. Samples were centrifuged and the pellets were washed twice using Model 5810R, Eppendorf centrifuge (Hamburg, Germany). Subsequently, the pellets obtained were freeze-dried and stored for analysis. Freeze-drying process were performed at

Table 2. Experimental design with designed composition parameters including experimental observed and predicted outcomes (NPs size and percentage drug recovered).

\begin{tabular}{ccccccccc}
\hline \multirow{2}{*}{$\begin{array}{c}\text { Standard } \\
\text { run }\end{array}$} & \multicolumn{2}{c}{ Composition parameters } & \multicolumn{2}{c}{ Experimental observed } & \multicolumn{2}{c}{ Predictions } \\
\cline { 2 - 8 } & $\begin{array}{c}\text { PLGA } \\
(\% \mathrm{w} / \mathrm{v})\end{array}$ & $\begin{array}{c}\text { Cip-HCl } \\
(\% \mathrm{w} / \mathrm{v})\end{array}$ & $\begin{array}{c}\text { PVA } \\
(\% \mathrm{w} / \mathrm{v})\end{array}$ & $\begin{array}{c}\text { Size } \\
(\mathrm{nm})\end{array}$ & $\begin{array}{c}\mathrm{DR} \\
(\% \mathrm{w} / \mathrm{w})\end{array}$ & $\begin{array}{c}\mathrm{DL} \\
(\% \mathrm{w} / \mathrm{w})\end{array}$ & $\begin{array}{c}\text { Size } \\
(\mathrm{nm})\end{array}$ & $\begin{array}{c}\text { DR } \\
(\% \mathrm{w} / \mathrm{w})\end{array}$ \\
\hline 1 & 1.0 & 0.5 & 0.1 & 443 & 5.85 & 1.125 & 443.00 & 5.85 \\
2 & 1.0 & 1.0 & 0.3 & 235 & 3.70 & 1.490 & 237.33 & 4.89 \\
3 & 1.0 & 1.5 & 0.2 & 302 & 1.70 & 0.990 & 299.67 & 0.51 \\
4 & 1.5 & 0.5 & 0.3 & 372 & 15.70 & 1.455 & 369.67 & 14.51 \\
5 & 1.5 & 1.0 & 0.2 & 384 & 4.28 & 1.425 & 384.00 & 4.28 \\
6 & 1.5 & 1.5 & 0.1 & 436 & 2.96 & 1.155 & 438.33 & 4.15 \\
7 & 2.0 & 0.5 & 0.2 & 347 & 8.86 & 1.055 & 349.33 & 10.05 \\
8 & 2.0 & 1.0 & 0.1 & 358 & 5.28 & 1.055 & 355.67 & 4.09 \\
9 & 2.0 & 1.5 & 0.3 & 353 & 3.21 & 1.120 & 353.00 & 3.21 \\
\hline $1 \mathrm{~V}$ & 1 & 0.2 & 0.1 & 530 & 7.83 & 1.618 & 558.84 & 10.01 \\
\hline $\mathrm{V}$ & 1 & 0.5 & 0.4 & 202 & 8.49 & 1.301 & 215.00 & 19.38 \\
\hline
\end{tabular}

DL: Drug Loading; DR: Drug Recovered. 
0.401 mbar and $-50^{\circ} \mathrm{C}$ for 48 hours using TELSTAR technologies S.L, LyoQuest-55 (Terrassa, Switzerland).

\subsection{Particles Size Analysis}

$10 \mathrm{mg}$ of lyophilized particles were dispersed into $5 \mathrm{ml}$ of distilled water and stirred gently for 15 minutes on a magnetic stirrer, the particles size were obtained by dynamic light scattering (NPs Size Analyzer, Model: SOS I, K-ONE (Seoul, South Korea)), the median hydrodynamic diameter (d50) of particles obtained by the instrument was considered as the NPs size (Table 2).

\subsection{Quantification of Drug Content}

$20 \mathrm{mg}$ of lyophilized particles were dispersed into $5 \mathrm{ml}$ chloroform and then 10 $\mathrm{ml}$ distilled water was added to extract $\mathrm{Cip}-\mathrm{HCl}$. The mixture was stirred on a magnetic stirrer for 3 hours to break down the polymer chains and subsequently evaporate the chloroform. The samples were centrifuge at $4000 \mathrm{rpm}$ for 15 minute to separate aqueous solution containing Cip- $\mathrm{HCl}$. Using a standard curve of known $\mathrm{Cip}-\mathrm{HCl}$ concentrations, separated $\mathrm{Cip}-\mathrm{HCl}$ solution were quantified by UV-spectrophotometer, CECIL CE 7250 (Cambridge, United Kingdom ) at a wavelengths of $279 \mathrm{~nm}$. The drug content was then transformed to percentage drug loading (Equation (1)) and percentage DR (Equation (2)).

$$
\begin{gathered}
\text { Drug loading } \%=\frac{\text { mass of drug in NPs }(\mathrm{mg})}{\text { mass of NPs recovered }(\mathrm{mg})} * 100 \% \\
\text { Drug Recovery } \%=\frac{\text { mass of drug in NPs }(\mathrm{mg})}{\text { mass of drug initially used }(\mathrm{mg})} * 100 \%
\end{gathered}
$$

\subsection{Drug Release}

$40 \mathrm{mg}$ of freeze-dried PLGA particles obtained from additional optimized experiments (experiments $1 \mathrm{~V}$ and $2 \mathrm{~V}$ ) were dispersed individually in $10 \mathrm{~mL}$ of PBS ( $\mathrm{pH} 7.4$ ), and were rotated on a Rotary mixer, Fan azmar gostar (Tehran, Iran) at $20 \mathrm{rpm}$ and room temperature. Samples $(2 \mathrm{~mL})$ were withdrawn for centrifugation for $20 \mathrm{~min}$ at $10,000 \mathrm{rpm}$ and $5^{\circ} \mathrm{C}$, and the supernatant were analyzed for drug content by UV spectroscopy at a wavelength of $279 \mathrm{~nm}$. The withdrawn volume were subsequently replaced with fresh release medium (PBS) between 1 - 24 hours.

\section{Results}

Results were discussed in terms of particles size, recovered Cip- $\mathrm{HCl}$ from PLGA NPs and the release of Cip- $\mathrm{HCl}$ from PLGA NPs. The drug loading is defined as the recovered amount of $\mathrm{Cip}-\mathrm{HCl}$ in the NPs obtained after the freeze-drying process of pellets obtained from centrifugation (Equation (1)). The DR is defined as the amount of $\mathrm{Cip}-\mathrm{HCl}$ recovered from NPs related to the amount of drugs initially used (Equation (2)). 


\section{Experimental Optimization and Validation Steps}

The results in Table 3 demonstrates the effect estimates obtained from two way linear to linear interactions of experimental formulation parameters on NPs size and DR. Quadratic effect of PLGA, linear effect of PVA and the interaction between PLGA and Cip-HCl shows to be statistically significant on NPs size due to their $p$-value below 0.05 . The effects of process parameters on percentage DR were observed to be statistically insignificant due to the $p$-value above 0.05 . Figure 1 and Figure 2 shows the Pareto chart which represents the standardized effect estimates ranked in order of significances of process parameters affecting NPs size and percentage DR respectively.

Table 3. Effect estimates on NPs size and percentage drug recovered.

\begin{tabular}{|c|c|c|c|c|c|c|}
\hline \multirow[t]{2}{*}{ Factor } & \multicolumn{3}{|c|}{ 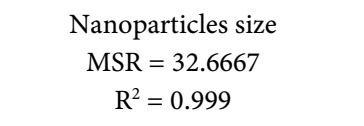 } & \multicolumn{3}{|c|}{$\begin{array}{c}\text { Drug recovered } \\
M S R=8.5443 \\
R^{2}=0.941\end{array}$} \\
\hline & Effect & Std.Err. & $p$-value & Effect & Std.Err. & $p$-value \\
\hline Mean/Interc. & 358.89 & 1.91 & 0.0034 & 5.73 & 0.97 & 0.1073 \\
\hline PLGA (L) & 26.00 & 4.67 & 0.1131 & 2.03 & 2.39 & 0.5508 \\
\hline PLGA (Q) & 57.67 & 4.04 & 0.0445 & 2.88 & 2.39 & 0.3963 \\
\hline Cip-HCl (L) & -23.67 & 4.67 & 0.1239 & -7.51 & 2.39 & 0.1958 \\
\hline Cip-HCl (Q) & -49.83 & 4.04 & 0.0515 & -1.96 & 2.07 & 0.5169 \\
\hline PVA (L) & -92.33 & 4.67 & 0.0321 & 2.84 & 2.39 & 0.4449 \\
\hline PVA Q) & 29.83 & 5.72 & 0.1205 & -3.09 & 2.92 & 0.4823 \\
\hline $\mathrm{PLGA}(\mathrm{L}){ }^{*} \mathrm{Cip}-\mathrm{HCl}(\mathrm{L})$ & 103.33 & 8.08 & 0.0497 & -3.84 & 4.13 & 0.5234 \\
\hline
\end{tabular}

MSR: Mean Square Residual; L: linear effect of composition parameters; Q: Quadratic effect of composition parameters; PLGA (L) * Cip-HCl (L): Linear interaction between PLGA and Cip-HCl; Std.Err: Standard error.

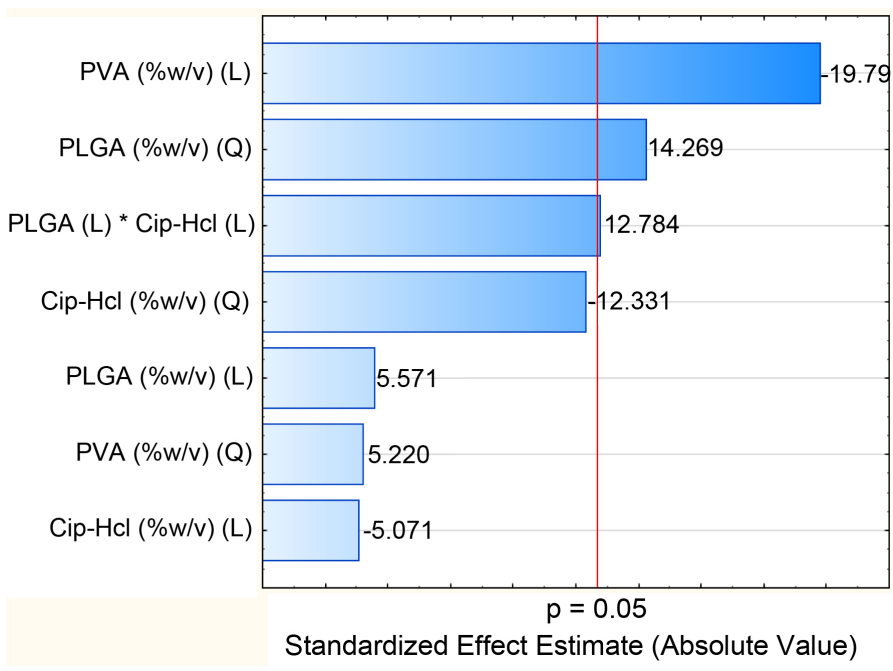

Figure 1. Pareto chart demonstrating standardized effects of composition parameters on NPs size ranked in their order of significances. L: linear effect of composition parameters; Q: Quadratic effect of composition parameters; PLGA (L) * $\mathrm{Cip}-\mathrm{HCl}(\mathrm{L})$ : Linear interaction between PLGA and Cip-HCl. 


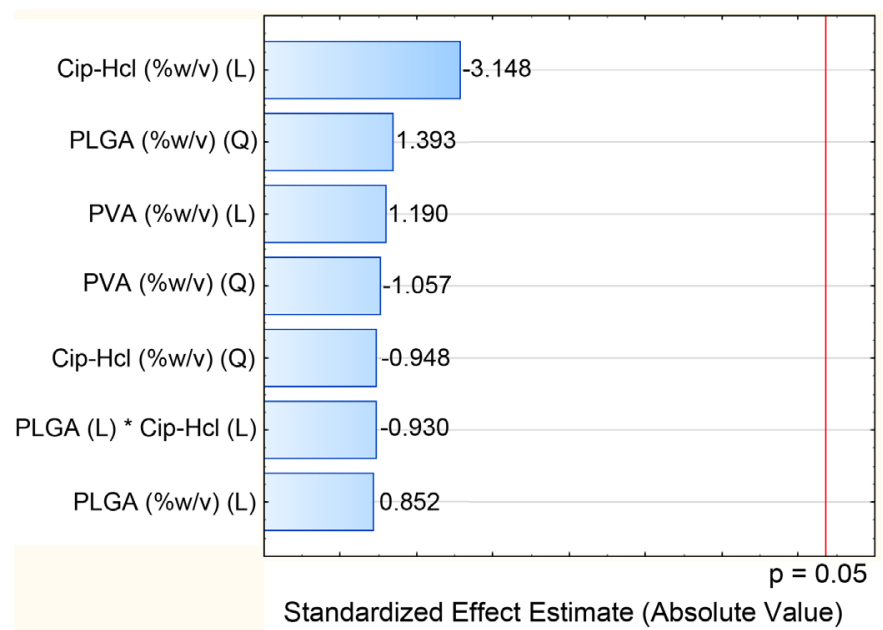

Figure 2. Pareto chart demonstrating the standardized effect of composition parameters on percentage drug recovered ranked in their order of significances. L: linear effect of composition parameters; Q: Quadratic effect of composition parameters; PLGA (L) * Cip-HCl (L): Linear interaction between PLGA and Cip- $\mathrm{HCl}$.

Equations (3) and (4) represent a model obtained from the regression analysis on FFD for the prediction of NPs size and percentage DR, with $\mathrm{X}_{1}, \mathrm{X}_{2}$ and $\mathrm{X}_{3}$ representing Concentrations of PLGA, Cip- $\mathrm{HCl}$ and PVA respectively. A good correlation was established between predicted and observed value as indicated by $\mathrm{R}^{2}=0.999$ on NPs size and $\mathrm{R}^{2}=0.941$ on DR. Mean square residual errors obtained in this model for the predictions of NPs size and percentage DR were 32.6666 and 8.544267 respectively, corresponding to standard error of 5.72 and 2.92 for both NPs and percentage DR (Standard error $=\sqrt{(\text { MS Residual })})$.

At a desirability values (Concentrations of PLGA $=2 \% \mathrm{w} / \mathrm{v}, \mathrm{Cip}-\mathrm{HCl}=$ $1.5 \% \mathrm{w} / \mathrm{v}$, and PVA $=0.3 \% \mathrm{w} / \mathrm{v})$, response surface curve at a two dimensional space of each parameters studied were generated to study their effects on NPs and percentage DR. Additional experiments $(1 \mathrm{~V}$ and $2 \mathrm{~V})$ were predicted from regression Equation (3) and Equation (4) prior to particles preparation. The optimized formulations $1 \mathrm{~V}$ and $2 \mathrm{~V}$ were observed to show similar results to predicted values on NPs size and minimal deviation on percentage DR.

Equation (3): Particle size

$$
\begin{aligned}
Y= & 332+511.33 X_{1}-230.67 X_{1}^{2}-732.33 X_{2}+199.33 X_{2}^{2} \\
& +732 X_{3}-2983 X_{3}^{2}+206.67 X_{1} * X_{2}
\end{aligned}
$$

Equation (4): Drug recovered

$$
\begin{aligned}
Y= & -11.34+44.27 X_{1}-11.52 X_{1}^{2}-11.67 X_{2}+7.84 X_{2}^{2} \\
& -109.4 X_{3}+309 X_{3}^{2}-7.68 X_{1} * X_{2}
\end{aligned}
$$

\section{Discussions}

\subsection{Effect of Process Parameters on NPs Size}

The particles size obtained were in the range between $202 \mathrm{~nm}$ to $530 \mathrm{~nm}$ which 
seems to be well suited for a drug delivery of $\mathrm{Cip}-\mathrm{HCl}$ in ophthalmic application in which the particles size should not exceed $10 \mu \mathrm{m}$ so as to avoid scratching [14]. Figures 3-5 shows that increasing simultaneously the concentrations of PLGA and Cip-HCl increases NPs size. The effect of PVA in Table 3 demonstrates that increasing the concentration of PVA either reduce (linear effect) or increase (Quadratic effect) NPs size.

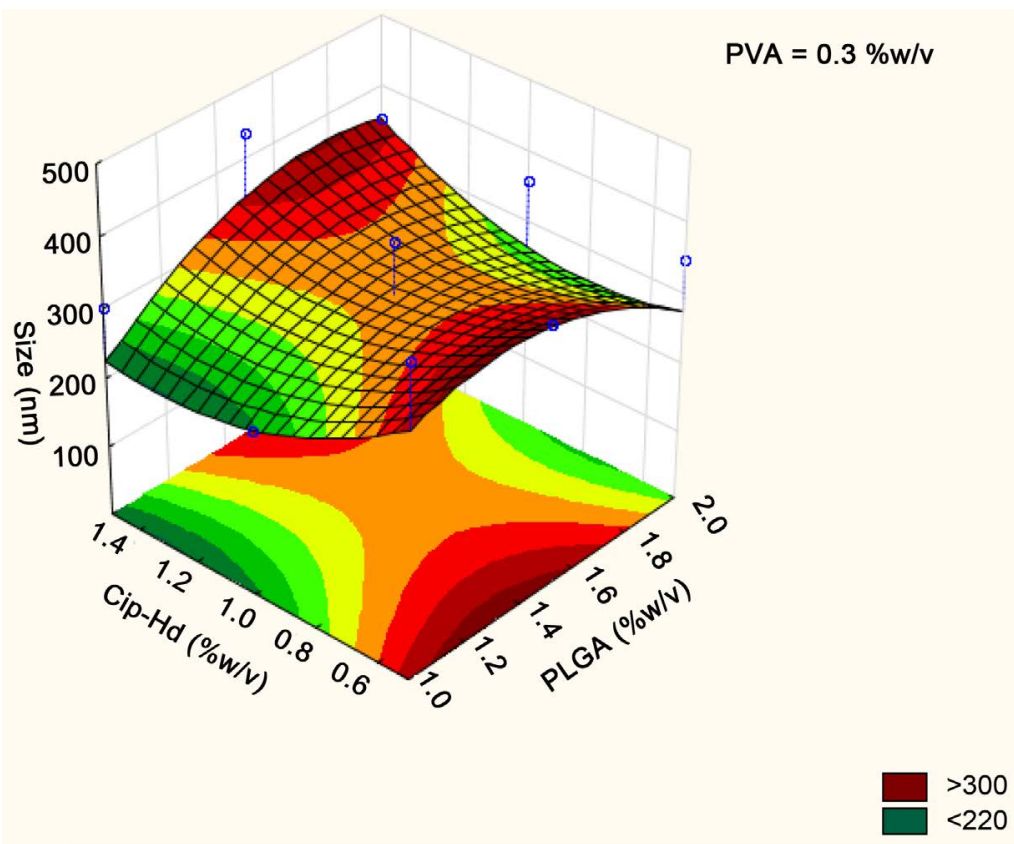

Figure 3. Response surface curve showing the interaction between PLGA and $\mathrm{Cip}-\mathrm{HCl}$ on particles size when PVA concentration is fixed at $0.3 \% \mathrm{w} / \mathrm{v}$.

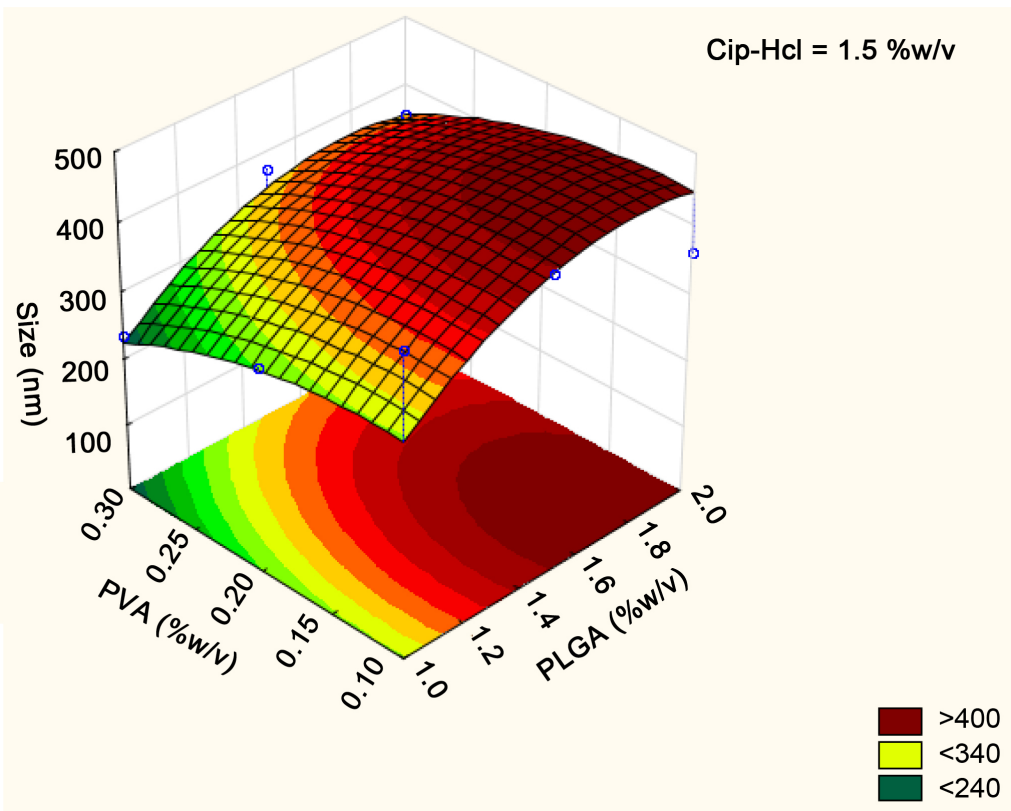

Figure 4. Response surface curve showing the interaction between PLGA and PVA on particles size when Cip- $\mathrm{HCl}$ concentration is fixed at $1.5 \% \mathrm{w} / \mathrm{v}$. 


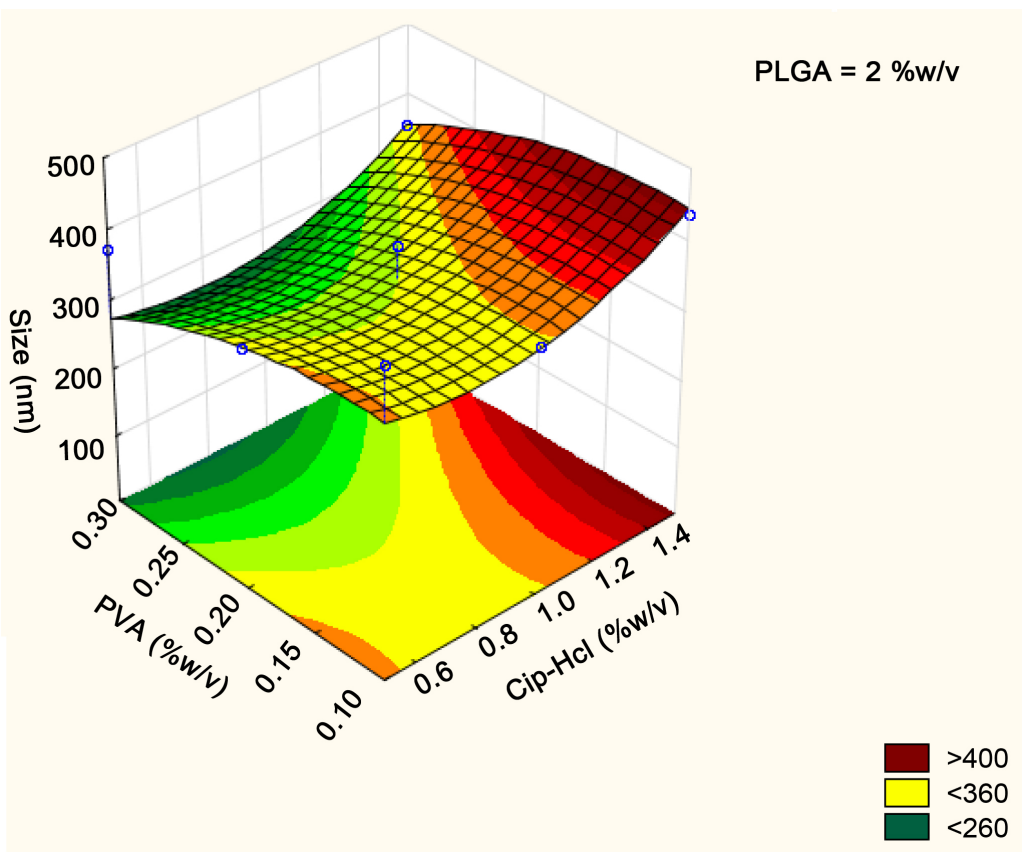

Figure 5. Response surface curve showing the interaction between Cip- $\mathrm{HCl}$ and PVA on particles size when PLGA concentration is fixed at $2 \% \mathrm{w} / \mathrm{v}$.

In similar work, Increasing PLGA concentration had been observed to increase the mean diameter of NPs [15]. Either an increase or reduction in the size of PLGA NPs has also been observed while increasing the concentration of PVA [16]. In recent studies, the size of PLGA NPs have been observed to be dependent on the viscosity of emulsion during preparation, such that, low viscosity emulsions results to small particles size and high viscosity emulsions result to higher particles size [17] [18].

Increase in the content of PLGA, Cip- $\mathrm{HCl}$ and PVA can leads to increment in viscosity of emulsion droplets and therefore leads to an increase in the size of PLGA NPs encapsulating Cip-HCl. However, linear effect of PVA in Figure 1 shows that increment in PVA concentration leads to reduction in NPs size and was observed to be the most significant effect affecting the particles size. While the effect of PVA concentration that leads to increment in NPs was observed to have a non-significant and negligible effect on NPs size (Quadratic effect of PVA). Therefore, the effect at which the concentration of PVA either reduce or increase the NPs is suggested to be attributed to stability and viscosity effect of the formulations.

\subsection{Effect of Process Parameters on Cip-HCl Recovery}

The percentage of Cip- $\mathrm{HCl}$ obtained from NPs after freeze drying process were in the range of 1.7 - 15.7, while the percentage drug loading reported were in the range of 0.99 - 1.49 (data not analyzed using statistical software). Increasing PLGA concentration was observed to increase the percentage DR after centrifugation. The increase in the amount of PVA was observed to either reduce or in- 
crease the percentage DR of NPs while the amount of Cip- $\mathrm{HCl}$ recovered from PLGA NPs was reduced at high concentration of Cip-Hcl. The Pareto chart of $\mathrm{DR}$ and Figure 6 shows that the amount of $\mathrm{Cip}-\mathrm{HCl}$ recovered increases while increasing the concentration of PLGA. However, Statistical analysis of effect estimates of composition parameters on percentage DR proves to be non-significant. A possible explanation could be attributed to excess PVA, non-encapsulated drug and some possible NPs removed during centrifugation/washing process, which might lead to lower percentage DR, even at high concentration of $\mathrm{Cip}-\mathrm{HCl}$. since the centrifugation parameters are responsible for the collection of particles at a certain range [19] [20].

In recent study, Low drug loading (1.9\%) of PLGA particles encapsulating ciprofloxacin prepared by $\mathrm{W} / \mathrm{O} / \mathrm{W}$ double emulsion solvent evaporation have also been reported by Dillen et al. [21].

Despite the level of insignificance, and centrifugation parameters, the effect of obtaining high percentage of drug in NPs can be attributed to the first emulsion process, such that, high concentration of PLGA at the organic phase can be able to encapsulate more Cip- $\mathrm{HCl}$ during the emulsification process. A justification for the low amount of experimental Cip-HCl loaded into PLGA NPs here in this study is suggested to be attributed to two possible unclear effects. The first effect is related to the concentrations of both PLGA and PVA, such that, an increase in their concentrations is equivalent to additional materials being introduced to each formulation which tends to reduce amount of Cip-Hcl recovered. The second effect might be attributed to when Cip-Hcl concentration is high, some Cip-Hcl might diffuse from first emulsion to the external aqueous phase of

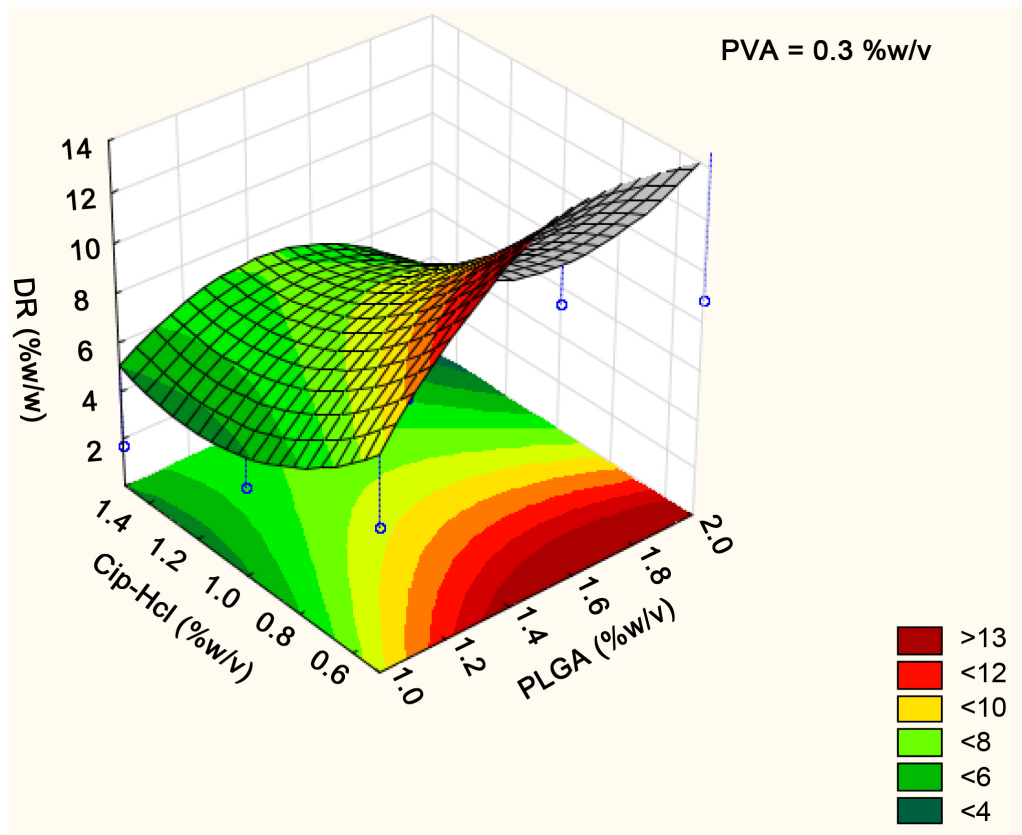

Figure 6. Responds surface curve demonstrating the interaction between PLGA and $\mathrm{Cip}-\mathrm{HCl}$ on percentage drug recovered when PVA concentration is fixed at $0.3 \% \mathrm{w} / \mathrm{v}$. 
double emulsion due to drug solubility in water. Nevertheless, it should be noted that percentage of Cip- $\mathrm{HCl}$ recovered can be attributed to the amount of NPs collected during the process of centrifugation.

\subsection{Drug Release}

In the present study, Figure 7 shows that the optimized formulations $(1 \mathrm{~V}$ and 2 V) followed a similar prolonged release of $\mathrm{Cip}-\mathrm{HCl}$ from PLGA NPs, approximately $41 \%-45 \%$ of Cip- $\mathrm{HCl}$ was released slowly without a burst release during $24 \mathrm{~h}$ from the PLGA NPs.

In recent studies, a slow release pattern of drugs has been observed from PLGA NPs [18] [22]. It has also been suggested that PVA as a stabilizer affects the release of drugs from polymeric particles [23]. Also another study suggests that due to larger surface area of NPs, PVA molecules on particles surface reduces the amount of drug released [24].

Although the majority of PVA, non-encapsulated drug and possibly some NPs were removed during centrifugation and washing steps. Here, we suggest two possible effects of controlled release of Cip-HCl from PLGA NPs. The first effect can be as a result of less $\mathrm{Cip}-\mathrm{HCl}$ on NPs surface, therefore erosion of the polymer chains or degradation of PLGA matrix might leads to controlled release of Cip-HCl from PLGA NPs. The second effect might be attributed to PVA attached to NPs surface which might cause a slow release of Cip- $\mathrm{HCl}$.

\section{Conclusion}

In this study, PLGA NPs encapsulating ciprofloxacin hydrochloride were prepared by water-oil-water $\left(\mathrm{W}_{1} / \mathrm{O} / \mathrm{W}_{2}\right)$ double emulsion solvent evaporation method. Technical parameters (volume of solvents used, stirring speed sonication and centrifugation parameters for NPs collection) of double emulsion were kept

\section{Drug Release}

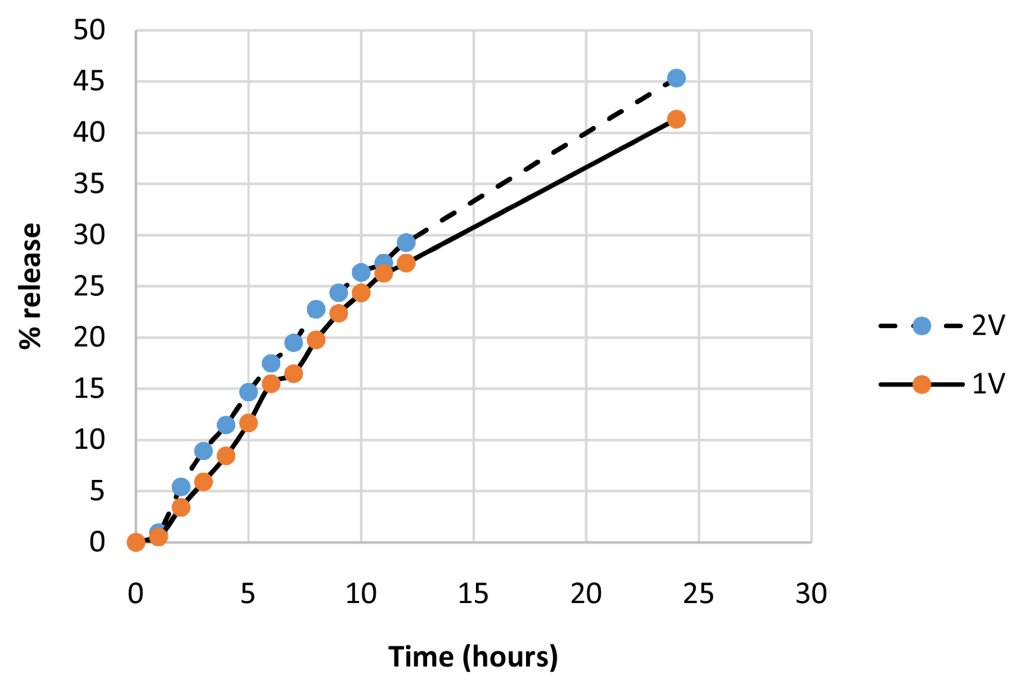

Figure 7. In- Vitro release of Cip-HCl from PLGA NPs. 
constant. The effects of composition parameters on NPs size and percentage drug recovery of PLGA NPs encapsulating ciprofloxacin hydrochloride were investigated by using a FFD. Composition parameters considered were concentrations of Ciprofloxacin Hydrochloride dissolved in inner aqueous phase $\left(\mathrm{W}_{1}\right)$, PLGA dissolved in chloroform phase (O), and PVA at external aqueous phase $\left(\mathrm{W}_{2}\right)$. Increasing the concentrations of composition parameters was observed to increase the NPs size, high concentration of PVA was also observed to reduce particles size. Increasing the concentration of PLGA was observed to increase percentage DR. Optimum formulations were obtained, equations to predict both particles sizes and percentage drug recovery of PLGA NPs were also derived. Furthermore, optimum formulations showed a prolonged release of ciprofloxacin hydrochloride from PLGA NPs within 1 - 24 hours. However, during experiments, centrifugation as a technical parameter was observed to affect the amount of drug recovered due to low amount of NPs collected. Conclusively, this experimental approach provides an optimum condition to produce PLGA NPs encapsulating ciprofloxacin hydrochloride for drug delivery applications.

\section{Acknowledgements}

Department of Medical Nanotechnology, School of Advanced Technologies in Medicine, International Campus, Tehran University of Medical Sciences, Iran.

\section{Conflict of Interests}

The authors declare that there is no conflict of interest.

\section{References}

[1] Alonso, M.J. (2004) Nanomedicines for Overcoming Biological Barriers. Biomedicine \& Pharmacotherapy, 58, 168-172. https://doi.org/10.1016/j.biopha.2004.01.007

[2] Ayodele, A.T., et al. (2017) Biointerface Research in Applied Chemistry. Ultrasound, 69,70 .

[3] Prego, C., et al. (2005) Nanomedicines for Overcoming Biological Barriers: Nanoparticles as a Carrier for Intestinal Drug Absorption. 2nd NanoSpain Workshop, Barcelona, March 14-17 2005.

[4] Chin, N.-X. and Neu, H.C. (1984) Ciprofloxacin, a Quinolone Carboxylic Acid Compound Active against Aerobic and Anaerobic Bacteria. Antimicrobial Agents and Chemotherapy, 25, 319-326. https://doi.org/10.1128/AAC.25.3.319

[5] Puga, A.M., et al. (2012) Hot Melt Poly- $\varepsilon$-Caprolactone/Poloxamine Implantable Matrices for Sustained Delivery of Ciprofloxacin. Acta Biomaterialia, 8, 1507-1518. https://doi.org/10.1016/j.actbio.2011.12.020

[6] Lesk, M.R., et al. (1993) The Penetration of Oral Ciprofloxacin into the Aqueous Humor, Vitreous, and Subretinal Fluid of Humans. American Journal of Ophthalmology, 115, 623-628. https://doi.org/10.1016/S0002-9394(14)71460-6

[7] Chaudhry, N.A., et al. (2000) Xanthomonas maltophilia Endophthalmitis after Cataract Surgery. Archives of Ophthalmology, 118, 572-575.

[8] Astete, C.E. and Sabliov, C.M. (2006) Synthesis and Characterization of PLGA Nanoparticles. Journal of Biomaterials Science, Polymer Edition, 17, 247-289. 
https://doi.org/10.1163/156856206775997322

[9] Breda, S.A., et al. (2009) Solubility Behavior and Biopharmaceutical Classification of Novel High-Solubility Ciprofloxacin and Norfloxacin Pharmaceutical Derivatives. International Journal of Pharmaceutics, 371, 106-113. https://doi.org/10.1016/j.ijpharm.2008.12.026

[10] Kasim, N.A., et al. (2004) Molecular Properties of WHO Essential Drugs and Provisional Biopharmaceutical Classification. Molecular Pharmaceutics, 1, 85-96. https://doi.org/10.1021/mp034006h

[11] Dillen, K., et al. (2006) Evaluation of Ciprofloxacin-Loaded Eudragit RS100 or RL100/PLGA Nanoparticles. International Journal of Pharmaceutics, 314, 72-82. https://doi.org/10.1016/j.ijpharm.2006.01.041

[12] Adebileje, T., Valizadeh, A. and Amani, A. (2017) Effect of Formulation Parameters on the Size of PLGA Nanoparticles Encapsulating Bovine Serum Albumin: A Response Surface Methodology. Journal of Contemporary Medical Sciences, 3, 306-312.

[13] Dejaegher, B. and Vander Heyden, Y. (2011) Experimental Designs and Their Recent Advances in Set-Up, Data Interpretation, and Analytical Applications. Journal of Pharmaceutical and Biomedical Analysis, 56, 141-158. https://doi.org/10.1016/j.jpba.2011.04.023

[14] Zimmer, A. and Kreuter, J. (1995) Microspheres and Nanoparticles Used in Ocular Delivery Systems. Advanced Drug Delivery Reviews, 16, 61-73. https://doi.org/10.1016/0169-409X(95)00017-2

[15] Song, X., et al. (2008) PLGA Nanoparticles Simultaneously Loaded with Vincristine Sulfate and Verapamil Hydrochloride: Systematic Study of Particle Size and Drug Entrapment Efficiency. International Journal of Pharmaceutics, 350, 320-329. https://doi.org/10.1016/j.ijpharm.2007.08.034

[16] Budhian, A., Siegel, S.J. and Winey, K.I. (2007) Haloperidol-Loaded PLGA Nanoparticles: Systematic Study of Particle Size and Drug Content. International Journal of Pharmaceutics, 336, 367-375. https://doi.org/10.1016/j.ijpharm.2006.11.061

[17] Haznedar, S. and Dortunc, B. (2004) Preparation and in Vitro Evaluation of Eudragit Microspheres Containing Acetazolamide. International Journal of Pharmaceutics, 269, 131-140. https://doi.org/10.1016/j.ijpharm.2003.09.015

[18] Hoffart, V., et al. (2002) Low Molecular Weight Heparin-Loaded Polymeric Nanoparticles: Formulation, Characterization, and Release Characteristics. Drug Development and Industrial Pharmacy, 28, 1091-1099. https://doi.org/10.1081/DDC-120014576

[19] Sahana, B., et al. (2010) Development of Biodegradable Polymer Based Tamoxifen citrate Loaded Nanoparticles and Effect of Some Manufacturing Process Parameters on Them: A Physicochemical and in-vitro Evaluation. International Journal of $\mathrm{Na}$ nomedicine, 5, 621-630.

[20] McCall, R.L. and Sirianni, R.W. (2013) PLGA Nanoparticles Formed by Single or Double-Emulsion with Vitamin E-TPGS. Journal of Visualized Experiments, 82, e51015.

[21] Dillen, K., et al. (2004) Factorial Design, Physicochemical Characterisation and Activity of Ciprofloxacin-PLGA Nanoparticles. International Journal of Pharmaceutics, 275, 171-187. https://doi.org/10.1016/j.ijpharm.2004.01.033

[22] Jiao, Y., et al. (2002) In Vitro and in Vivo Evaluation of Oral Heparin-Loaded Polymeric Nanoparticles in Rabbits. Circulation, 105, 230-235. 
https://doi.org/10.1161/hc0202.101988

[23] Panyam, J., et al. (2003) Polymer Degradation and in Vitro Release of a Model Protein from Poly (D, L-lactide-co-glycolide) Nano- and Microparticles. Journal of Controlled Release, 92, 173-187. https://doi.org/10.1016/S0168-3659(03)00328-6

[24] Korsmeyer, R.W. and Peppas, N.A. (1981) Effect of the Morphology of Hydrophilic Polymeric Matrices on the Diffusion and Release of Water Soluble Drugs. Journal of Membrane Science, 9, 211-227. https://doi.org/10.1016/S0376-7388(00)80265-3 